\title{
əon the Optimal Measuring Area for Pointwise Rainfall Estimation: A Dedicated Experiment with 14 Laser Disdrometers
}

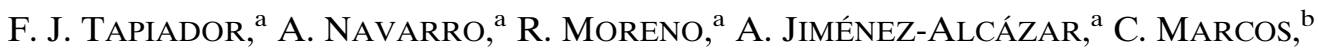 \\ A. Tokay, ${ }^{\mathrm{c}}$ L. Durán, ${ }^{\mathrm{d}}$ J. M. Bodoque, ${ }^{\mathrm{e}}$ R. Martín, ${ }^{\mathrm{f}}$ W. Petersen, ${ }^{\mathrm{g}}$ AND M. De CAStro ${ }^{\mathrm{a}}$

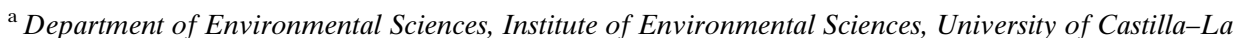 \\ Mancha, Toledo, Spain \\ ${ }^{\mathrm{b}}$ Spanish Meteorological Agency (AEMET), Madrid, Spain \\ ${ }^{\mathrm{c}}$ Code 612, NASA Goddard Space Flight Center, Greenbelt, Maryland \\ ${ }^{\mathrm{d}}$ InterMET S.L., Madrid, Spain \\ ${ }^{\mathrm{e}}$ Department of Geology and Mining Engineering, University of Castilla-La Mancha, Toledo, Spain \\ ${ }^{\mathrm{f}}$ Department of Mathematics, University of Castilla-La Mancha, Toledo, Spain \\ ${ }^{\mathrm{g}}$ Earth Science Office, NASA Marshall Space Flight Center, Huntsville, Alabama
}

(Manuscript received 2 June 2016, in final form 12 December 2016)

\begin{abstract}
Laser disdrometers measure the particle size distribution (PSD) of hydrometeors through a small cross-sectional (tens of square centimeters) surface. Such a limited area induces a sampling effect in the estimates of the PSD, which translates to error in the reflectivity-rain-rate $(Z-R)$ relationship used for ground radar estimates of rainfall, estimates of kinetic energy of precipitation, and any other hydrometeorological application relying on particle size information. Here, the results of a dedicated experiment to estimate the extent of the effect of limited area sampling of rainfall are presented. Using 14 Parsivel, version 1 (Parsivel-1), disdrometers placed within $6 \mathrm{~m}^{2}$, it was found that the combined area of at least seven disdrometers is required for the estimates to start converging to a stable value. The results can be used to quantify the degree of over-/underestimation of precipitation parameters for a single instrument due to the limited collecting area effect. It has been found that a single disdrometer may underestimate instantaneous rain rate by $70 \%$.
\end{abstract}

\section{Introduction}

Direct estimates of the particle size distribution (PSD) are required for a variety of hydrological studies, for instance, for precise water resources assessment (Lee and Zawadzki 2006; Ten Veldhuis et al. 2014), soil erosion analyses (Winder and Paulson 2012; Salles et al. 2002; Petan et al. 2010; Lim et al. 2015), and in remote sensing of precipitation from space (Bringi et al. 2003; Gorgucci et al. 2001; Thurai et al. 2010; Liao et al. 2014). The relationship between the reflectivity $Z$ and rainfall rate $R$ is the basis of rainfall estimation using single-polarization radar. The $a$ prefactor and the $b$ exponent in the $Z=a R^{b}$ formula are derived by a $\log -\log$ regression of coincident

¿ Denotes content that is immediately available upon publication as open access.

Corresponding author e-mail: Francisco J. Tapiador, francisco. tapiador@uclm.es estimates of instantaneous $Z$ and $R$ over a period (Marshall et al. 1955; Battan 1973). Verification of this relationship requires good measurements of the PSD.

For dual-polarimetric instruments, the PSD is still required, as the differential reflectivity $Z_{\mathrm{dr}}$ and, to a lesser extent, the specific differential phase $K_{\mathrm{dp}}$ still depend on the PSD and assumptions on the shape of the distribution have to be made (Gorgucci et al. 2002; Chandrasekar and Bringi 1988; Xiao and Chandrasekar 1997). Therein, pointwise estimates of precipitation are still needed to calibrate and verify both ground and spaceborne radars such as the TRMM PR or the Global Precipitation Measurement (GPM) Dual-Frequency Precipitation Radar (DPR).

Measurements from disdrometers (from distribution of drops meters) are deemed the most direct estimates of the PSD. This kind of instrument has been proved crucial for several aspects of hydrological science. Thus, disdrometers have been employed to analyze the microstructure of rain events (Jameson et al. 2016; Ignaccolo et al. 2009), including its spatiotemporal 
structure in 3D (Gires et al. 2015); characterize the PSD in flood events (Friedrich et al. 2016); delineate flood areas (Beauchamp et al. 2015); assist radars to estimate the spatial correlation of the PSD (Bringi et al. 2015; Thurai et al. 2012); develop new algorithms (Anagnostou et al. 2013); verify quantitative precipitation estimates from weather radars (Bringi et al. 2011; Gourley et al. 2009); perform hydrological validation of nowcastings (Berenguer et al. 2005); study radio signal propagation (Montopoli et al. 2008; Watson and Hodges 2009); and carry out error analysis at catchment scale (Jordan et al. 2003).

Laser disdrometers measure the PSD of liquid and solid hydrometeors using a collimated, flat laser beam of negligible width and small cross-sectional area. The actual size depends on the manufacturer, but it is on the order of tens of square centimeters. Thus, for instance, Parsivel, version 1 (Parsivel-1), disdrometers have a $180 \mathrm{~mm} \times 30 \mathrm{~mm}$ area $\left(54 \mathrm{~cm}^{2}\right)$, Thies's disdrometer (Frasson et al. 2011) has a $228 \mathrm{~mm} \times 20 \mathrm{~mm}$ area $\left(46 \mathrm{~cm}^{2}\right)$, and the optical-spectro pluviometer (OSP; Hauser et al. $1984)$ has a $250 \mathrm{~mm} \times 40 \mathrm{~mm}$ area $\left(100 \mathrm{~cm}^{2}\right)$. Another type of disdrometer, the Joss-Waldvogel disdrometer (JWD; Löffler-Mang and Joss 2000), has an area of about $50 \mathrm{~cm}^{2}$, whereas 2D video disdrometers (2DVDs; Kruger and Krajewski 2002) are in the range of $100 \mathrm{~cm}^{2}$. Infraredlight-emitting-diode-based Optical Disdrometer Measuring unit (ODM470; Lempio et al. 2007) has a $26.4 \mathrm{~cm}^{2}$ cross-sectional area.

Such limited areas introduce a bias in the estimation of precipitation parameters such as radar reflectivity and total rainfall, which are directly derived from the PSD. Even allowing for the (somehow strong) ergodic hypothesis, small accumulation intervals mean a bias against large, less-frequent drops. Small intercept area is not the only source of error, however. For the case of the Parsivel disdrometers, several other problems and issues have arisen, such as limitations in measuring very small or very large drops because of noise and small catching area, respectively, or the existence of "margin fallers" (cf. Jaffrain and Berne 2011; Raupach and Berne 2015; Yuter et al. 2006; You and Lee 2015). Most notably, Battaglia et al. (2010) have discussed the problems when dealing with solid precipitation.

All the potential error sources contribute to increase the uncertainty in determining the PSD, which is a must for precise quantification of the hydrological cycle. However, no experiment has been devised to specifically address the issue of how large the measuring area of a disdrometer has to be for a reliable estimate of precipitation parameters.

As part of Spain's contribution to the ground validation segment of the NASA-JAXA GPM mission, an

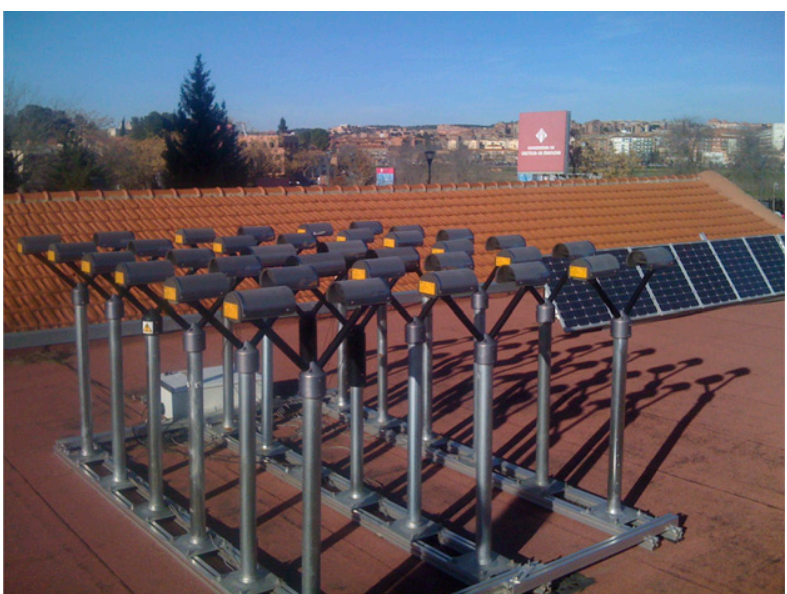

FIG. 1. Setup of the experiment: 18 laser disdrometers collocated as close as possible (Toledo, Spain). The instruments at the center are two Parsivel-2 instruments that were not used for this experiment. The two Parsivel-1 instruments most uncorrelated with the rest were not used for the calculations, resulting in the experiment based in 14 disdrometers.

experiment was designed to elucidate the extent of the bias due to the limited area of the disdrometers. The main novelties of the experiment presented here are the actual setup, with very close separations between the instruments, and the number of identical instruments employed to address the research question.

\section{Data and methods}

\section{a. Setup}

Sixteen identical Parsivel-1 disdrometers were used for the experiment. Using the same type of instrument is important to rule out confounding factors in the analyses (Tokay et al. 2013, 2016).

The disdrometers were aligned and carefully leveled so they presented the same cross section to falling rain. The instruments were calibrated at the factory by the manufacturer, but an additional check was performed upon arrival at the University of Castilla-La Mancha (UCLM) by dropping dielectric spheres of several sizes through the center of the laser beams to make sure the instruments were capable of detecting the size.

To minimize the spatial decorrelation with distance (Berne et al. 2012; Tapiador et al. 2010; Tokay and Bashor 2010), the disdrometers were placed as close as possible within a $\sim 6 \mathrm{~m}^{2}$ area (Fig. 1). For such small distances, the spatial decorrelation is negligible for the purposes of the experiment [see the results in Tapiador et al. (2010)] and turbulence is assumed to equally affect all the instruments; the same applies to the individual instrument error factor. Figure 1 shows two additional 
Parsivel, version 2 (Parsivel-2), instruments that were located at the center of the array, but these were not used for this experiment.

Direct readings every minute from the disdrometers were converted into two-dimensional histograms of diameter and terminal speed. Data were then accumulated to a standard 5-min accumulation period and filtered for spurious readings.

Toledo's climate is semiarid (about $342 \mathrm{~mm} \mathrm{yr}^{-1}$ ), which makes precipitation a precious resource. Maximum precipitation accumulations are in May and December. The aridity represents a challenge for building a database with statistically representative case studies, as a large part of the total rain comes from brief and scattered episodes across the year.

\section{b. Filtering}

The data were filtered in 2016 with the latest version of NASA GPM quality control software, as follows. This ensures homogeneity of the database with other experiments within the GPM mission. Parsivel disdrometer raw output is the drop counts $C_{i, k}$ at 32 size bins $i$ and 32 fall velocity bins $k$. The raindrop concentration at a given size bin $i$ [Eq. (1)] is the ratio of drop counts across all fall velocity bins divided by period of observations $t$, cross-sectional area, measured fall velocity $v_{k}$, and bin width $\Delta D_{i}$. Given the fact that the laser beam is $180 \mathrm{~mm}$ long and $30 \mathrm{~mm}$ wide, there is a possibility of partially observed drops. To count these margin fallers accurately, cross-sectional area is calculated as a function of drop size $A\left(D_{i}\right)=180(30-D / 2)$ (Jaffrain et al. 2011):

$$
n_{i}=\sum_{i=1}^{n} \sum_{k=1}^{m} \frac{C_{i, k}}{t A\left(D_{i}\right) v_{k} \Delta D_{i}} .
$$

Parsivel raw output can be retrieved at $10 \mathrm{~s}$ as being the highest temporal resolution. Traditionally, the DSD is calculated at 1-min interval. The small drops reach their terminal fall speed quite rapidly, and it is challenging to distinguish the "real" drops from secondary drops that are basically splash from the two concavedown helmets of the instrument. A size versus fall velocity binary matrix is used to distinguish the secondary drops from real drops (Fig. 2). The matrix also allows discarding anomalous readings such as insects, leaves, and other particles. The in/out area is based on the Atlas et al. (1973) expression for terminal velocity at ground level: $v(D)=965-1030 \exp (-6 D)$, with $v(D)$ in meters per second and $D$ in centimeters. As comparison, the curve of Atlas and Ulbrich (2000), $v(D)=3.78 D^{0.67}$ ( $D$ in millimeters), is also shown.

The data were then filtered again so only those intervals with at least 10 drops in all the instruments were

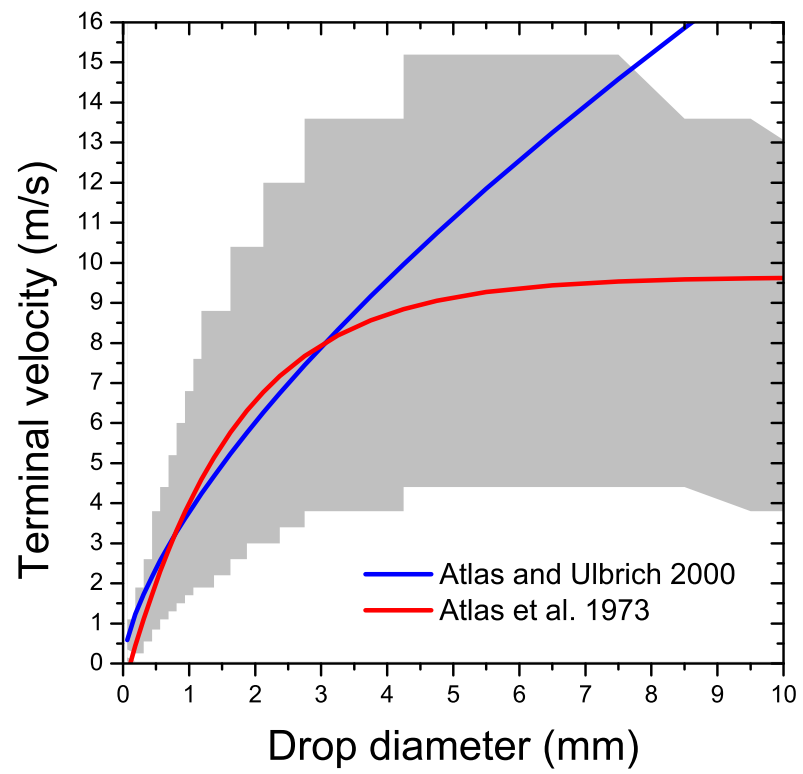

FIG. 2. Matrix used to filter the raw disdrometer data, featuring Atlas et al. (1973) and Atlas and Ulbrich (2000) relationships for terminal velocities as a function of raindrop diameter. Drops outside the shaded area are discarded.

kept. This avoids having rain in just one part of the array, a situation that can happen at the beginning and end of rainy episodes. For reference, the product from the process is tagged as the "UCLM disdrometer database v3.0." This 2016 database supersedes and replaces previous versions of UCLM's disdrometer data.

\section{c. Processing}

Four cases were selected corresponding to 21 April, 7 May, 6 June, and 7 June 2011. Figure 3 shows the rainfall time series. After processing, data from 16 disdrometers were cross correlated to detect systematic anomalous readings. It was found that two instruments yielded different measurements from the other 14 in terms of cross correlation for integral parameters, so the data from those were removed. Further processing was done with the data of the remaining 14 instruments (12 in the case of the June data).

The variables of interest were derived from

$$
p(D)=n(D, A, t)
$$

where $p(D)$ is the PSD as a function of drop diameter $D$, area of measurement $A$, and time instant $t$, and from

$$
M^{\alpha}(A, t)=\sum_{D} D^{\alpha} p(D) \Delta D
$$

which are the moments of order $\alpha$ of the $p(D)$. From Eqs. (2) and (3), the rain rate $R=M^{3.67}$, the equivalent 
$21 / 04 / 2011$
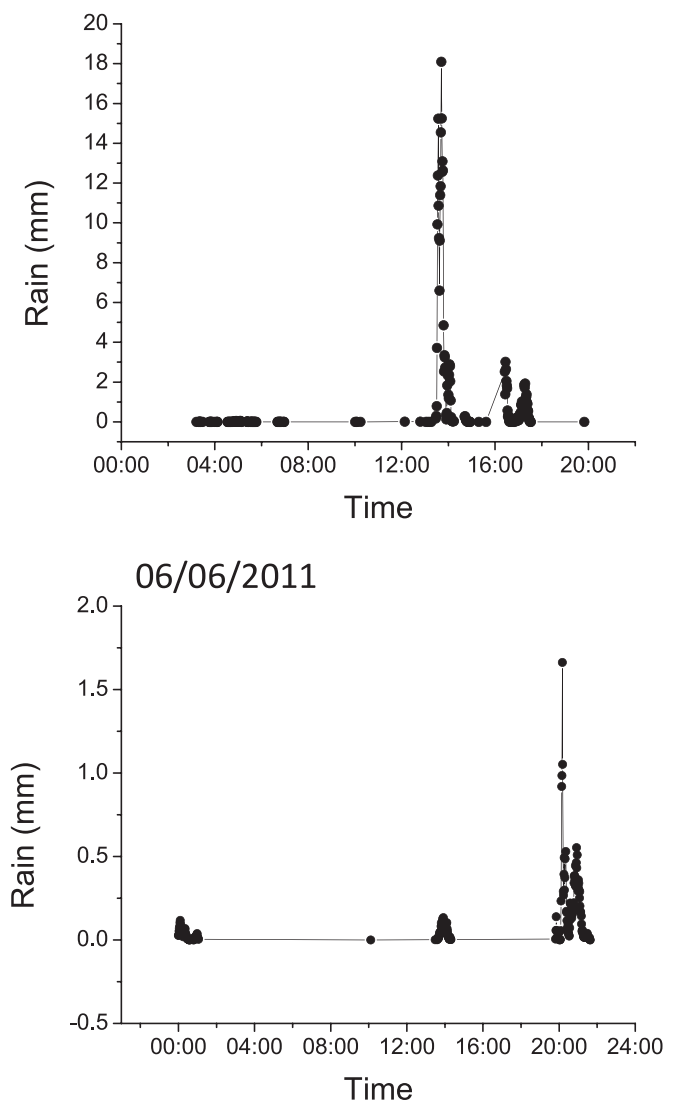

$07 / 05 / 2011$

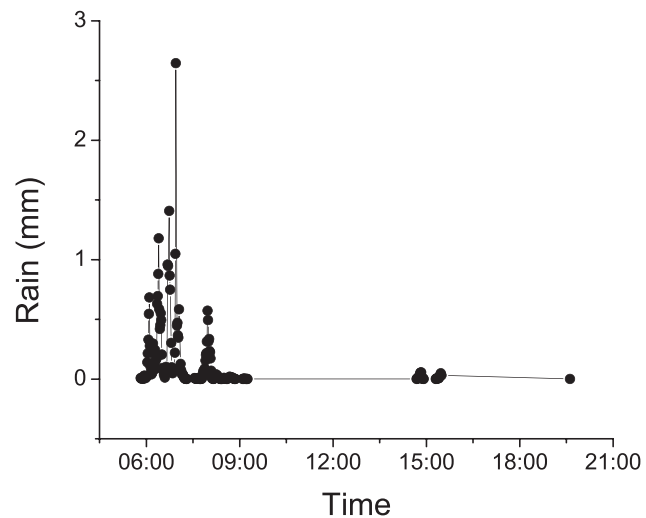

$07 / 06 / 2011$

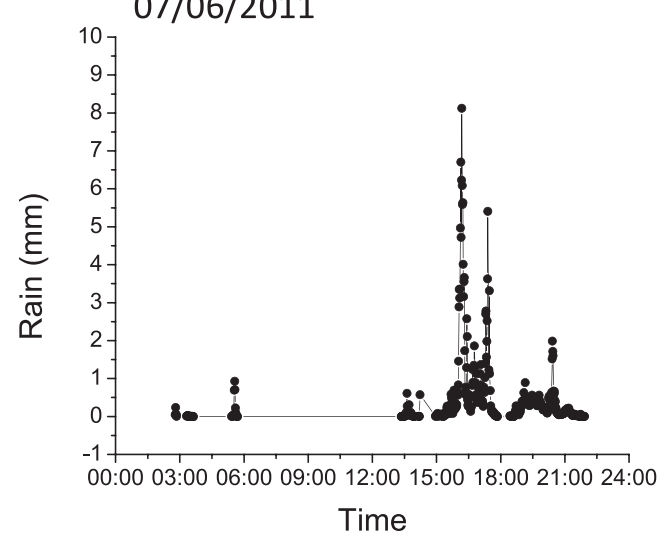

FIG. 3. Time series of rain for the four cases used for the experiment.

radar reflectivity $Z=M^{6}$, the mass-weighted drop diameter $D_{\text {mass }}=M^{4} / M^{3}$, and the maximum diameter $D_{\max }$ is the maximum value of $D$ within the distribution. No parametric form was assumed for deriving the integral parameters in order to make the results independent from functional forms of the PSD such as the gamma distribution.

To simulate different measurement areas we considered variable sets of disdrometers within the $\sim 6 \mathrm{~m}^{2}$ measuring area. Each set describes a possible arrangement of the considered disdrometer, and it is made up by a group of $r$ disdrometers (regardless of how they are positioned within the experimental area) among the total of $m$ working instruments (see Fig. 4 for a toy example). The total number of set (or arrangements) is found to be, from basic combinatory analysis,

$$
C_{r}^{m}=\left(\begin{array}{ll}
m & r
\end{array}\right)^{\mathrm{T}},
$$

which is the number of combinations without repetition. Therein, in our case, $m=14$ and $r$ is variable from 1 to $m$, leading to a total of 16369 arrangements (91 for $r=2$ instruments, 3432 for $r=7$, and so on). Each arrangement of $r$ disdrometers corresponds to a simulated measurement area $A_{S}$ equal to $\left(A_{S}=r A_{D}\right)$, where $A_{D}$ is the actual measurement area of the disdrometer $\left(A_{D}=54 \mathrm{~cm}^{2}\right.$ in the case of Parsivel disdrometers).

The processing was as follows: every possible arrangement of, say, $r$ disdrometers was treated as a single disdrometer of $r$-times $54 \mathrm{~cm}^{2}$ area. In other words, any drop coming from any of the $r$ disdrometers was treated as a drop in an $r$-times $54 \mathrm{~cm}^{2}$ single disdrometer and processed as such. Repeating the procedure for all the possible combinations yields $\left(\begin{array}{ll}n & r\end{array}\right)^{\mathrm{T}}$ equivalent measurements of the $r$ disdrometers. The statistics from such an ensemble are thus considered as the nominal values that would be measured by an $r$-times $54 \mathrm{~cm}^{2}$ synthetic instrument.

An example will clarify the method. For 3 disdrometers taken out of 14 , there are 364 possible arrangements, that is, (14 3$)^{\mathrm{T}}$, so, for instance, the $(3,11,14)$ combination. The data for each one of these arrangements were processed for calculating the $R, Z, D_{\text {mass }}$, and $D_{\max }$ for a $54 \times 3 \mathrm{~cm}^{2}$ area. 


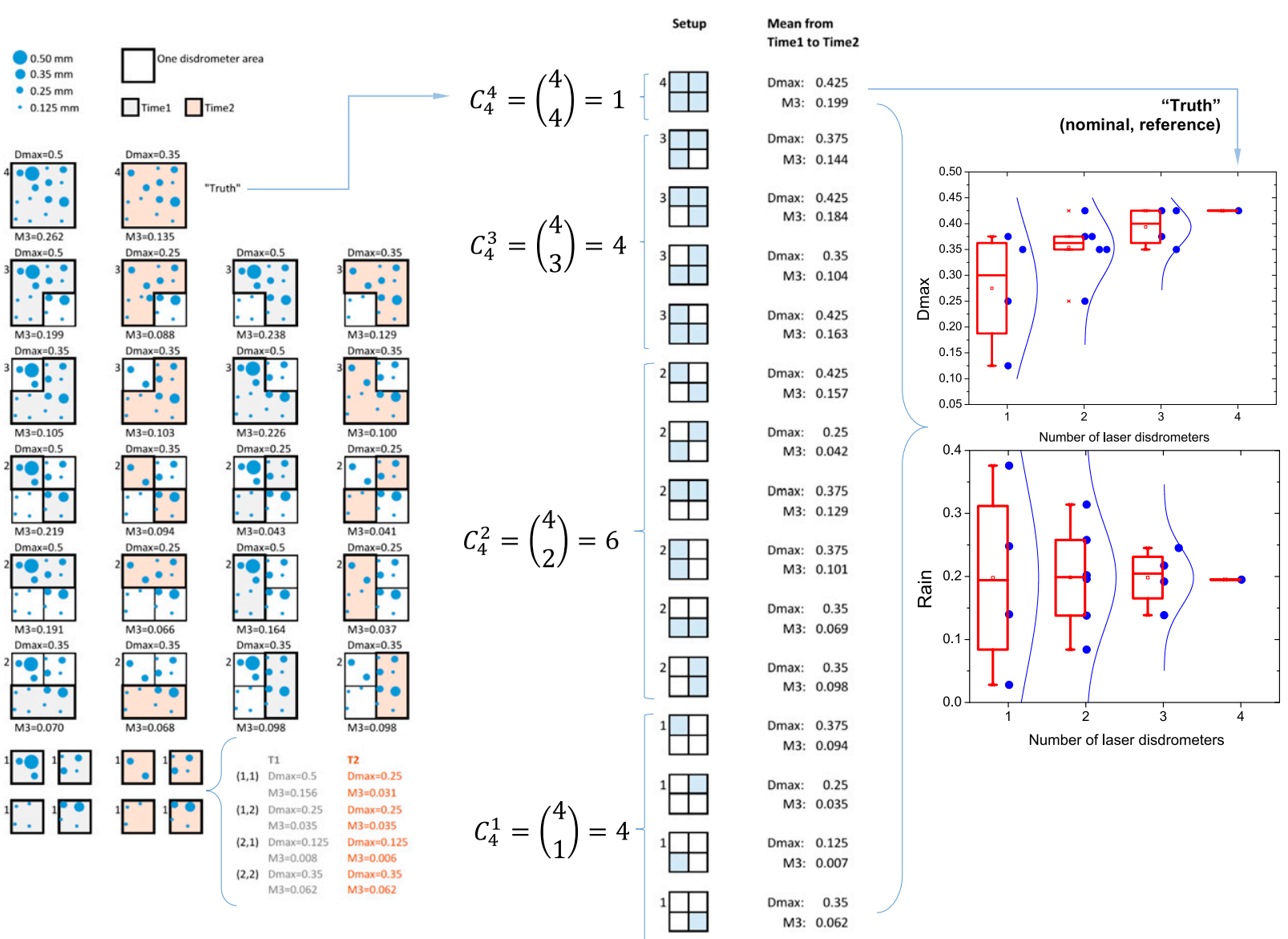

FIG. 4. Toy example to illustrate the processing. All the possible combinations of $m=4$ disdrometers are used to derive $D_{\max }$ (diameter of the largest drop) and $M^{3}$ (proportional to rain) for just two sequential and highly correlated PSDs at time instants $T_{1}$ and $T_{2}$. The temporal mean derived from each individual arrangement of $r$ instruments is then compared with all the $C_{4}^{r}=\left(\begin{array}{ll}4 & r\end{array}\right)^{\mathrm{T}}$ arrangements $($ box plots on the right). The actual experiment used $m=14$ disdrometers and several hundreds of 1-min intervals of real precipitation.

The same was done for any number of disdrometers. Thus, for 10 disdrometers, there are 1001 possible arrangements, for example, the $(1,2,4,6,7,10,11,12,13,14)$. The resulting $R, Z, D_{\text {mass }}$, and $D_{\max }$ from each one of the arrangements are thus members of a population of 1001 members. The statistics of such an ensemble, chiefly the mean value, represent what would be measured by a single disdrometer of $540 \mathrm{~cm}^{2}$ area. Note that this procedure is not at all equivalent to combining the statistics of processed data from individual disdrometers.

More formally, let $n\left(D, A_{i}^{r}, t\right)$ be the PSD as a function of drop diameter $D$, simulated area of measurement of the $i$ th arrangement when $k$ instruments are considered $\left(A=A_{i}^{r}\right)$, and time instant $t$. Let $M^{\alpha}\left(A_{i}^{r}, t\right)=\sum_{D} D^{\alpha} n\left(D, A_{i}^{r}, t\right) \Delta D$ be the moment of order $\alpha$ of $n\left(D, A_{i}^{r}, t\right)$, and let $M^{\alpha}\left(A_{i}^{r}, \Delta t\right)$ be the time average of $M^{\alpha}\left(A_{i}^{r}, \Delta t\right)$ over the period $\Delta t$. Thus, for $k$ from 1 to $m$, we have a set of $m$ different values for the measurement area, and for each of them we have a distribution of $M^{\alpha}\left(A_{i}^{r}, \Delta t\right)$. The latter explains the different combinations of the position of $r$ disdrometers that produce the same measurement area. The quantity $M^{\alpha}\left(A_{i}^{r}, \Delta t\right)$ for $r=1, \ldots, 14$ is that used to calculate $Z, R, D_{\text {mass }}$, and $D_{\max }$.

\section{Results}

Figure 5 synthetizes the main results of the experiment. It shows PSD estimates as a function of the number of disdrometers used for deriving them. The plot thus illustrates how the estimates of the PSD parameters depend on the area of measurement.

The value in the setup of 14 disdrometers, that is, the value of the largest possible measurement area $\left(756 \mathrm{~cm}^{2}\right)$, is taken as the reference. Such number acts as the nominal value of the experiment for each variable insofar as it represents the best possible guess given the instruments available, and therefore a reference for 
$21 / 04 / 2011$
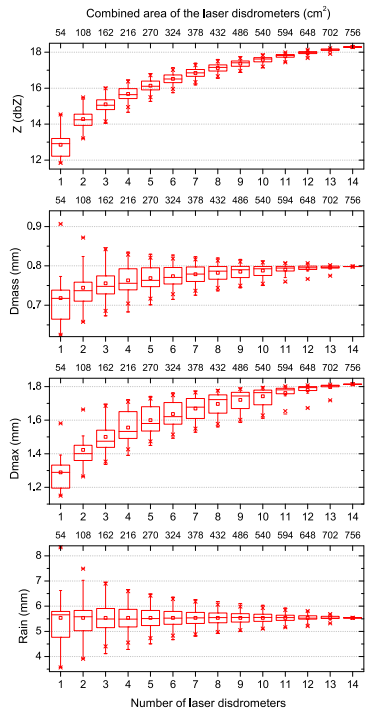

$07 / 05 / 2011$
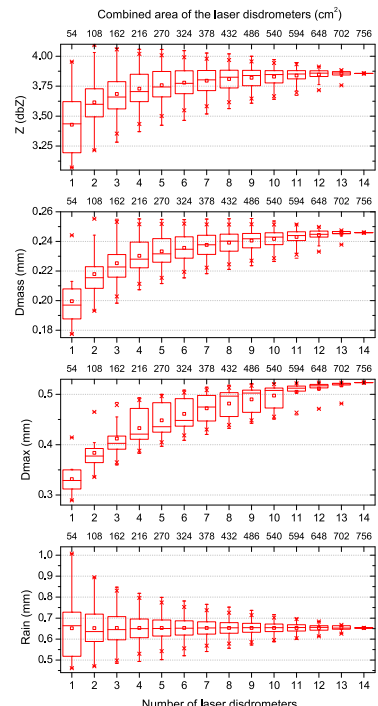

$06 / 06 / 2011$
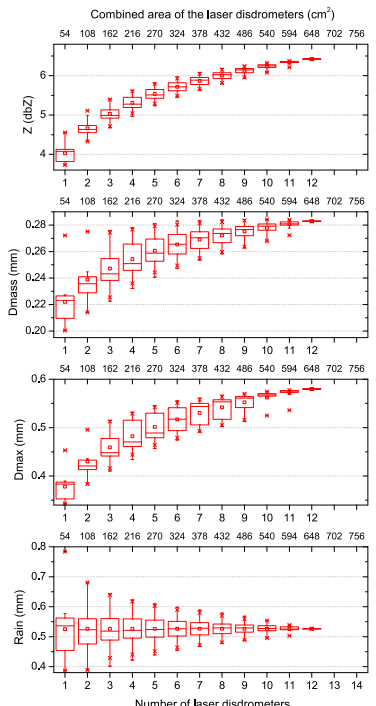

$07 / 06 / 2011$
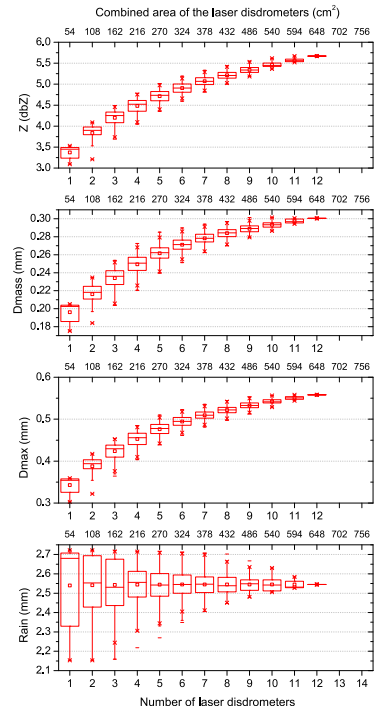

FIG. 5. Estimates of $Z, D_{\text {mass }}, D_{\max }$, and $R$ as a function of the number of disdrometers used for deriving the parameters, for four cases. The reflectivity is not corrected by area to illustrate such effect. The box plots represent the dispersion of the ensemble of combinations for each number of instruments, taking into account all the possible combinations (without repetition); the short dashes are the extremes; the square is the mean; crosses are the $99 \%$ and $1 \%$ ranges; the box range is the 25 and 75 percentiles; and the range of the whiskers indicates outliers with a 1.5 coefficient. The horizontal lines inside the boxes represent the medians.

the rest of the setups. The boxplots represent the dispersion of the ensemble for each number of instruments taking into account all the possible combinations of each number of disdrometers. For the only possible combination of all the instruments, the dispersion is obviously null.

There is a common pattern in Fig. 5 for the key variables reported here: $Z, D_{\text {mass }}, D_{\max }$, and $R$. As the number of instruments and thus the simulated measurement area increases, the dispersion seems to stabilize after a stepped slope. Thus, for $D_{\max }$, the mean of all the possible onedisdrometer setups yields relatively large spreads. As the number of disdrometers grows, the dispersion reduces and, more importantly, the nominal estimate of $D_{\max }$ starts to converge. When the number of disdrometers reaches 7 , the tendency stabilizes and little variation follows. Further increase in the number of disdrometers reduces the spread, but the value of the variable is already stable enough to conclude asymptotic convergence to the reference value.

\section{Conclusions}

The results of the experiment indicate that a measuring area of at least $378 \mathrm{~cm}^{2}$ is required to minimize the sampling effect in the estimation of radar reflectivity and drop size parameters with laser disdrometers. This value is a minimum, and repeating the experiment in other climate regimes, locations, and seasons may yield different values. While in this case seven disdrometers sufficed to emulate a larger setup of 14 collocated instruments, in some other cases the number of instruments to achieve convergence may vary. However, the present experiment yields a lower limit that can only be increased (not lowered, as there is one case requiring at least seven instruments).

While it is always recommended using at least two instruments to quality check the results, most laser disdrometers operate in isolation. But even for dual setups, most of the disdrometric estimates in the literature present a known error due to the limited measuring area of the instrument. This is something that can be easily verified with experiments such as the one described here. Under the light of the results in this paper and on top of other corrections, the estimates from a single disdrometer should be corrected to avoid under-/overestimation of precipitation moments and integral parameters over the area of which the instrument is supposed to be representative.

Errors larger than $70 \%$ can be found in the moments of the distribution. Instantaneous rainfall rate, which is critical for hydrological studies, is likely to be always severely underestimated by a single disdrometer. In the case of $D_{\text {mass }}$ and $D_{\max }$, the tendency is also to underestimate the actual value. This is sensible, as large drops are relatively less frequent in time and more scattered in space and are therefore more unlikely to be found crossing a small area than small- and medium-sized drops. By missing many large drops (lower $D_{\max }$ ), the 
whole PSD shifts to the left and that results in lower $D_{\text {mass, }}$, and therein in an underestimation of $R$ and $Z$.

New experiments using a similar setup as the one described can help to correlate the errors with precipitation regimes and/or rainfall intensity, increasing the number of disdrometers required from the seven suggested in this paper. In any case, it is clear that a single disdrometer cannot provide a suitable instantaneous estimate of the hydrological variables of interest.

The same applies to rain gauges as the catching area of these instruments is similar. As a rule of thumb, the estimates of instantaneous rainfall rate from a single instrument can be off by about $70 \%$. The observation has immediate consequences in terms of validation and verification of weather and climate models with rain gauges and can help explain the discrepancies found between satellite- and ground-based precipitation estimates.

To conclude, it is worth mentioning that the setup is intended to carry out a "Gedankenexperiment" (thought experiment), and not to suggest actually building a megadisdrometer with a sampling area of $756 \mathrm{~cm}^{2}$ or larger. Even if technological constraints would allow such instrument to be built, the larger number of drops simultaneously crossing the laser is likely to make outputs less reliable given the operational principle of laser disdrometers.

Acknowledgments. Funding from projects CGL201348367-P, CGL2016-80609-R (Ministerio de Economía y Competitividad), UNCM08-1E-086 (Ministerio de Ciencia e Innovacion), and CYTEMA (UCLM) is gratefully acknowledged. The disdrometer network was made possible thanks to European Fund for Economic and Regional Development (FEDER) funds. The authors also wish to acknowledge fruitful discussions in the Particle Size Distribution Working Group (PSDWG) of the Global Precipitation Measurement (GPM) mission. Special thanks are due to Ana Barros, Alexis Berne, Bob Houze, Chris Kummerow, GyuWon Lee, and Merhala Thurai for their constructive comments when the results were first presented in public, and to the four anonymous referees who also helped improve the paper. W.A.P. acknowledges support from the NASA Precipitation Science (Ramesh Kakar) and GPM programs (Gail. S-J. Jackson and Mathew Schwaller).

\section{REFERENCES}

Anagnostou, M. N., J. Kalogiros, F. S. Marzano, E. N. Anagnostou, M. Montopoli, and E. Piccioti, 2013: Performance evaluation of a new dual-polarization microphysical algorithm based on long-term X-band radar and disdrometer observations. J. Hydrometeor., 14, 560-576, doi:10.1175/JHM-D-12-057.1.

Atlas, D., and C. W. Ulbrich, 2000: An observationally based conceptual model of warm oceanic convective rain in the tropics. J. Appl. Meteor., 39, 2165-2181, doi:10.1175/ 1520-0450(2001)040<2165:AOBCMO > 2.0.CO;2.

_ R. C. Srivastava, and R. S. Sekhon, 1973: Doppler radar characteristics of precipitation at vertical incidence. Rev. Geophys. Space Phys., 11, 1-35, doi:10.1029/RG011i001p00001.

Battaglia, A., E. Rustemeier, A. Tokay, U. Blahak, and C. Simmer, 2010: Parsivel snow observations: A critical assessment. J. Atmos. Oceanic Technol., 27, 333-344, doi:10.1175/ 2009JTECHA1332.1.

Battan, L. J., 1973: Radar Observations of the Atmosphere. University of Chicago Press, $324 \mathrm{pp}$.

Beauchamp, R. M., V. Chandrasekar, H. Chen, and M. Vega, 2015: Overview of the D3R observations during the IFloodS field experiment with emphasis on rainfall mapping and microphysics. J. Hydrometeor., 16, 2118-2132, doi:10.1175/JHM-D-15-0023.1.

Berenguer, M., C. Corral, R. Sánchez-Diezma, and D. SempereTorres, 2005: Hydrological validation of a radar-based nowcasting technique. J. Hydrometeor., 6, 532-549, doi:10.1175/ JHM433.1.

Berne, A., J. Jaffrain, and M. Schleiss, 2012: Scaling analysis of the variability of the rain drop size distribution at small scale. $A d v$. Water Resour., 45, 2-12, doi:10.1016/j.advwatres.2011.12.016.

Bringi, V. N., V. Chandrasekar, J. Hubbert, E. Gorgucci, W. L. Randeu, and M. Schönhuber, 2003: Raindrop size distribution in different climatic regimes from disdrometer and dualpolarized radar analysis. J. Atmos. Sci., 60, 354-365, doi:10.1175/ 1520-0469(2003)060<0354:RSDIDC >2.0.CO;2.

, M. A. Rico-Ramirez, and M. Thurai, 2011: Rainfall estimation with an operational polarimetric C-band radar in the United Kingdom: Comparison with a gauge network and error analysis. J. Hydrometeor., 12, 935-954, doi:10.1175/JHM-D-10-05013.1.

, L. Tolstoy, M. Thurai, and W. A. Petersen, 2015: Estimation of spatial correlation of drop size distribution parameters and rain rate using NASA's S-band polarimetric radar and 2D video disdrometer network: Two case studies from MC3E. J. Hydrometeor., 16, 1207-1221, doi:10.1175/JHM-D-14-0204.1. Chandrasekar, V., and V. N. Bringi, 1988: Error structure of multiparameter radar and surface measurements of rainfall. Part I: Differential reflectivity. J. Atmos. Oceanic Technol., 5, 783-795, doi:10.1175/1520-0426(1988)005<0783:ESOMRA > 2.0.CO;2.

Frasson, R. P. de M., L. K. da Cunha, and W. F. Krajewski, 2011: Assessment of the Thies optical disdrometer performance. Atmos. Res., 101, 237-255, doi:10.1016/j.atmosres.2011.02.014.

Friedrich, K., E. A. Kalina, J. Aikins, M. Steiner, D. Gochis, P. A. Kucera, K. Ikeda, and J. Sun, 2016: Raindrop size distribution and rain characteristics during the 2013 Great Colorado Flood. J. Hydrometeor., 17, 53-72, doi:10.1175/JHM-D-14-0184.1.

Gires, A., I. Tchiguirinskaia, D. Schertzer, and A. Berne, 2015: 2DVD data revisited: Multifractal insights into cuts of the spatiotemporal rainfall process. J. Hydrometeor., 16, 548-562, doi:10.1175/JHM-D-14-0127.1.

Gorgucci, E., G. Scarchilli, V. Chandrasekar, and V. N. Bringi, 2001: Rainfall estimation from polarimetric radar measurements: Composite algorithms immune to variability in raindrop shape-size relation. J. Atmos. Oceanic Technol., 18, 1773-1786, doi:10.1175/1520-0426(2001)018<1773: REFPRM $>2.0 . \mathrm{CO} ; 2$.

, V. Chandrasekar, V. N. Bringi, and G. Scarchilli, 2002: Estimation of raindrop size distribution parameters from polarimetric radar measurements. J. Atmos. Sci., 59, 2373-2384, doi:10.1175/1520-0469(2002)059<2373:EORSDP > 2.0.CO;2.

Gourley, J. J., D. P. Jorgensen, S. Y. Matrosov, and Z. L. Flamig, 2009: Evaluation of incremental improvements to quantitative 
precipitation estimates in complex terrain. J. Hydrometeor., 10, 1507-1520, doi:10.1175/2009JHM1125.1.

Hauser, D., P. Amayenc, B. Nutten, and P. Waldteufel, 1984: A new optical instrument for simultaneous measurement of raindrop diameter and fall speed distributions. J. Atmos. Oceanic Technol., 1, 256-269, doi:10.1175/1520-0426(1984)001<0256: ANOIFS $>2.0 . \mathrm{CO} ; 2$.

Ignaccolo, M., C. De Michele, and S. Bianco, 2009: The droplike nature of rain and its invariant statistical properties. J. Hydrometeor., 10, 79-95, doi:10.1175/2008JHM975.1.

Jaffrain, J., and A. Berne, 2011: Experimental quantification of the sampling uncertainty associated with measurements from Parsivel disdrometers. J. Hydrometeor., 12, 352-370, doi:10.1175/ 2010JHM1244.1.

—, A. Atudzinski, and A. Berne, 2011: A network of disdrometers to quantify the small-scale variability of the raindrop size distribution. Water Resour. Res., 47, W00H06, doi:10.1029/ 2010WR009872.

Jameson, A. R., M. L. Larsen, and A. B. Kostinski, 2016: An example of persistent microstructure in a long rain event. J. Hydrometeor., 17, 1661-1673, doi:10.1175/JHM-D-15-0180.1.

Jordan, P. W., A. W. Seed, and P. E. Weinmann, 2003: A stochastic model of radar measurement errors in rainfall accumulations at catchment scale. J. Hydrometeor., 4, 841-855, doi:10.1175/ 1525-7541(2003)004<0841:ASMORM>2.0.CO;2.

Kruger, A., and W. F. Krajewski, 2002: Two-dimensional video disdrometer: A description. J. Atmos. Oceanic Technol., 19, 602-617, doi:10.1175/1520-0426(2002)019<0602: TDVDAD $>2.0 . \mathrm{CO} ; 2$.

Lee, G., and I. Zawadzki, 2006: Radar calibration by gage, disdrometer, and polarimetry: Theoretical limit caused by the variability of drop size distribution and application to fast scanning operational radar data. J. Hydrol., 328, 83-97, doi:10.1016/j.jhydrol.2005.11.046.

Lempio, G. E., K. Bumke, and A. Macke, 2007: Measurement of solid precipitation with an optical disdrometer. $A d v$. Geosci., 10, 91-97, doi:10.5194/adgeo-10-91-2007.

Liao, L., R. Meneghini, and A. Tokay, 2014: Uncertainties of GPM DPR rain estimates caused by DSD parameterizations. J. Appl. Meteor. Climatol., 53, 2524-2537, doi:10.1175/ JAMC-D-14-0003.1.

Lim, Y. S., J. K. Kim, J. W. Kim, B. I. Park, and M. S. Kim, 2015: Analysis of the relationship between the kinetic energy and intensity of rainfall in Daejeon, Korea. Quat. Int., 384, 107117, doi:10.1016/j.quaint.2015.03.021.

Löffler-Mang, M., and J. Joss, 2000: An optical disdrometer for measuring size and velocity of hydrometeors. J. Atmos. Oceanic Technol., 17, 130-139, doi:10.1175/1520-0426(2000)017<0130: AODFMS $>2.0 . \mathrm{CO} ; 2$.

Marshall, J., W. Hitchfeld, and K. Gunn, 1955: Advances in radar weather. Advances in Geophysics, Vol. 2, Academic Press, 1-56, doi:10.1016/S0065-2687(08)60310-6.

Montopoli, M., F. S. Marzano, and G. Vulpiani, 2008: Analysis and synthesis of raindrop size distribution time series from disdrometer data. IEEE Trans. Geosci. Remote Sens., 46, 466-478, doi:10.1109/TGRS.2007.909102.

Petan, S., S. Rusjan, A. Vidmar, and M. Mikoš, 2010: The rainfall kinetic energy-intensity relationship for rainfall erosivity estimation in the Mediterranean part of Slovenia. J. Hydrol., 391, 314-321, doi:10.1016/j.jhydrol.2010.07.031.
Raupach, T. H., and A. Berne, 2015: Correction of raindrop size distributions measured by Parsivel disdrometers, using a twodimensional video disdrometer as a reference. Atmos. Meas. Tech., 8, 343-365, doi:10.5194/amt-8-343-2015.

Salles, C., J. Poesen, and D. Sempere-Torres, 2002: Kinetic energy of rain and its functional relationship with intensity. J. Hydrol., 257, 256-270, doi:10.1016/S0022-1694(01)00555-8.

Tapiador, F. J., R. Checa, and M. de Castro, 2010: An experiment to measure the spatial variability of rain drop size distribution using sixteen laser disdrometers. Geophys. Res. Lett., 37, L16803, doi:10.1029/2010GL044120.

Ten Veldhuis, J. A. E., and Coauthors, 2014: High resolution radar rainfall for urban pluvial flood management: Lessons learnt from 10 pilots in north-west Europe within the RainGain project. 13th IWA/IAHR Int. Conf. on Urban Drainage, Sarawak, Malaysia, International Water Association, 2518234. [Available online at http://www.raingain.eu/sites/default/files/ icud2014_raingain_submission.pdf.]

Thurai, M., V. N. Bringi, and P. T. May, 2010: CPOL radarderived drop size distribution statistics of stratiform and convective rain for two regimes in Darwin, Australia. J. Atmos. Oceanic Technol., 27, 932-942, doi:10.1175/ 2010JTECHA1349.1.

, — , L. D. Carey, P. Gatlin, E. Schultz, and W. A. Petersen, 2012: Estimating the accuracy of polarimetric radar-based retrievals of drop-size distribution parameters and rain rate: An application of error variance separation using radarderived spatial correlations. J. Hydrometeor., 13, 1066-1079, doi:10.1175/JHM-D-11-070.1.

Tokay, A., and P. G. Bashor, 2010: An experimental study of smallscale variability of raindrop size distribution. J. Appl. Meteor. Climatol., 49, 2348-2365, doi:10.1175/2010JAMC2269.1.

_ W. W. Petersen, P. Gatlin, and M. Wingo, 2013: Comparison of raindrop size distribution measurements by collocated disdrometers. J. Atmos. Oceanic Technol., 30, 1672-1690, doi:10.1175/JTECH-D-12-00163.1.

— L. P. D'Adderio, D. B. Wolff, and W. A. Petersen, 2016: A field study of pixel-scale variability of raindrop size distribution in the mid-Atlantic region. J. Hydrometeor., 17, 18551868, doi:10.1175/JHM-D-15-0159.1.

Watson, R. J., and D. D. Hodges, 2009: Estimation of rainfall rate from terrestrial microwave link measurements. Proc. 2009 IEEE Int. Geoscience and Remote Sensing Symp., Vol. 3, Cape Town, South Africa, IEEE, III-263-III-266, doi:10.1109/ IGARSS.2009.5417770

Winder, P., and K. S. Paulson, 2012: The measurement of rain kinetic energy and rain intensity using an acoustic disdrometer. Meas. Sci. Technol., 23, 015801, doi:10.1088/0957-0233/23/1/ 015801.

Xiao, R., and V. Chandrasekar, 1997: Development of a neural network based algorithm for rainfall estimation from radar observations. IEEE Trans. Geosci. Remote Sens., 35, 160-171, doi:10.1109/36.551944.

You, C. H., and D. I. Lee, 2015: Decadal variation in raindrop size distributions in Busan, Korea. Adv. Meteor., 2015, 329327, doi:10.1155/2015/329327.

Yuter, S. E., D. E. Kingsmill, L. B. Nance, and M. Löffler-Mang, 2006: Observations of precipitation size and fall speed characteristics within coexisting rain and wet snow. J. Appl. Meteor. Climatol., 45, 1450-1464, doi:10.1175/JAM2406.1. 